\title{
The depth of pseudotachylyte formation from detailed thermochronology and constraints on coseismic stress drop variability
}

\author{
J. D. Kirkpatrick, ${ }^{1,2}$ K. J. Dobson, ${ }^{3,4}$ D. F. Mark, ${ }^{5}$ Z. K. Shipton, ${ }^{3,6}$ E. E. Brodsky, ${ }^{2}$ \\ and F. M. Stuart ${ }^{5}$
}

Received 20 September 2011; revised 4 April 2012; accepted 17 April 2012; published 23 June 2012.

[1] Pseudotachylytes are accepted as recording paleo-seismicity in the rock record. However, the interpretation of the mechanics of faulting based on pseudotachylyte generation is often hindered because the depth at which they form is poorly constrained. Here, we use thermochronology to determine the depth at which pseudotachylytes in the Sierra Nevada, California, formed. The pseudotachylytes formed in $\leq 10 \mathrm{~m}$ long patches over a rupture surface, the rest of which comprised cataclasites that did not melt. The age of the pseudotachylytes is found to be $76.6 \pm 0.3 \mathrm{Ma}(2 \sigma)$ from ${ }^{40} \mathrm{Ar} /{ }^{39} \mathrm{Ar}$ dating of pristine vein matrix. A suite of thermochronometers define the temperature-time path of the host rock granodiorite from $\sim 550$ to $60^{\circ} \mathrm{C}$. When the pseudotachylytes formed, the ambient temperature was 110 to $160^{\circ} \mathrm{C}$, implying a depth of $\sim 2.4$ to $6.0 \mathrm{~km}$ under typical geothermal gradients. At these depths, the failure stress on optimally oriented faults with Byerlee friction and hydrostatic pore pressure was $\leq 51 \mathrm{MPa}$. Following melting, the dynamic stress acting on the fault is the melt shear resistance, which we calculate to be $<0.2 \mathrm{MPa}$, suggesting that the stress drop associated with melting was complete. To conform with seismologically observed dynamic stress drops averaged over an entire rupture (1 to $10 \mathrm{MPa}$ ), dynamic stress drop must have varied by at least an order of magnitude between the parts of the fault that melted and those that did not.

Constraining the depth of pseudotachylyte formation using thermochronology therefore provides a quantitative estimate of the degree and scale of coseismic stress heterogeneity.

Citation: Kirkpatrick, J. D., K. J. Dobson, D. F. Mark, Z. K. Shipton, E. E. Brodsky, and F. M. Stuart (2012), The depth of pseudotachylyte formation from detailed thermochronology and constraints on coseismic stress drop variability, J. Geophys. Res., 117, B06406, doi:10.1029/2011JB008846.

\section{Introduction}

[2] Tectonic pseudotachylytes are the chilled remnants of frictionally induced melts found along fault surfaces [Philpotts, 1964]. The temperature rise required for melting implies that seismic slip rates (of the order of 0.1 to $1 \mathrm{~m} / \mathrm{s}$ ) are necessary for pseudotachylytes to form during a slip

\footnotetext{
${ }^{1}$ Formerly at School of Geographical and Earth Sciences, University of Glasgow, Glasgow, UK.

${ }^{2}$ Department of Earth and Planetary Science, University of California, Santa Cruz, California, USA.

${ }^{3}$ School of Geographical and Earth Sciences, University of Glasgow, Glasgow, UK.

${ }^{4}$ Now at Manchester X-ray Imaging Facility, School of Materials, University of Manchester, Manchester, UK. UK.

${ }^{5}$ Scottish Universities Environmental Research Centre, East Kilbride,

${ }^{6}$ Now at Department of Civil and Environmental Engineering, University of Strathclyde, Glasgow, UK.

Corresponding author: J. D. Kirkpatrick, Department of Earth and Planetary Science, University of California, Santa Cruz, CA 95064, USA. (jkirkpat@ucsc.edu)

(C)2012. American Geophysical Union. All Rights Reserved. 0148-0227/12/2011JB008846
}

event [Sibson, 1975]. Currently, pseudotachylytes are the only recognized indicator of ancient seismic activity in exposures containing exhumed faults [Cowan, 1999] and as such, they provide a unique tool for investigating seismic processes from the rock record.

[3] The presence of pseudotachylyte can place constraints on the stress state on the fault during rupture because for a given amount of slip, frictional heating is dependent on the shear stress if all of the mechanical work during slip is converted to heat [Sibson, 2003]. Some studies use the required temperature rise to estimate the average dynamic shear stress acting on the fault over the duration of slip [Sibson, 1975; Barker, 2005; Di Toro et al., 2005; Andersen et al., 2008]. However, interpreting the derived stress in terms of laboratory constraints on friction requires additional knowledge about the normal stress on the faults. Any further connection between the stress and the micromechanics of resistance rests on inferences about the depth of the pseudotachylyte formation [e.g., Fialko and Khazan, 2005], as the lithostatic stress places a minimum bound on the normal stress.

[4] Despite its importance, the depth of pseudotachylyte formation is often difficult to directly determine, particularly 

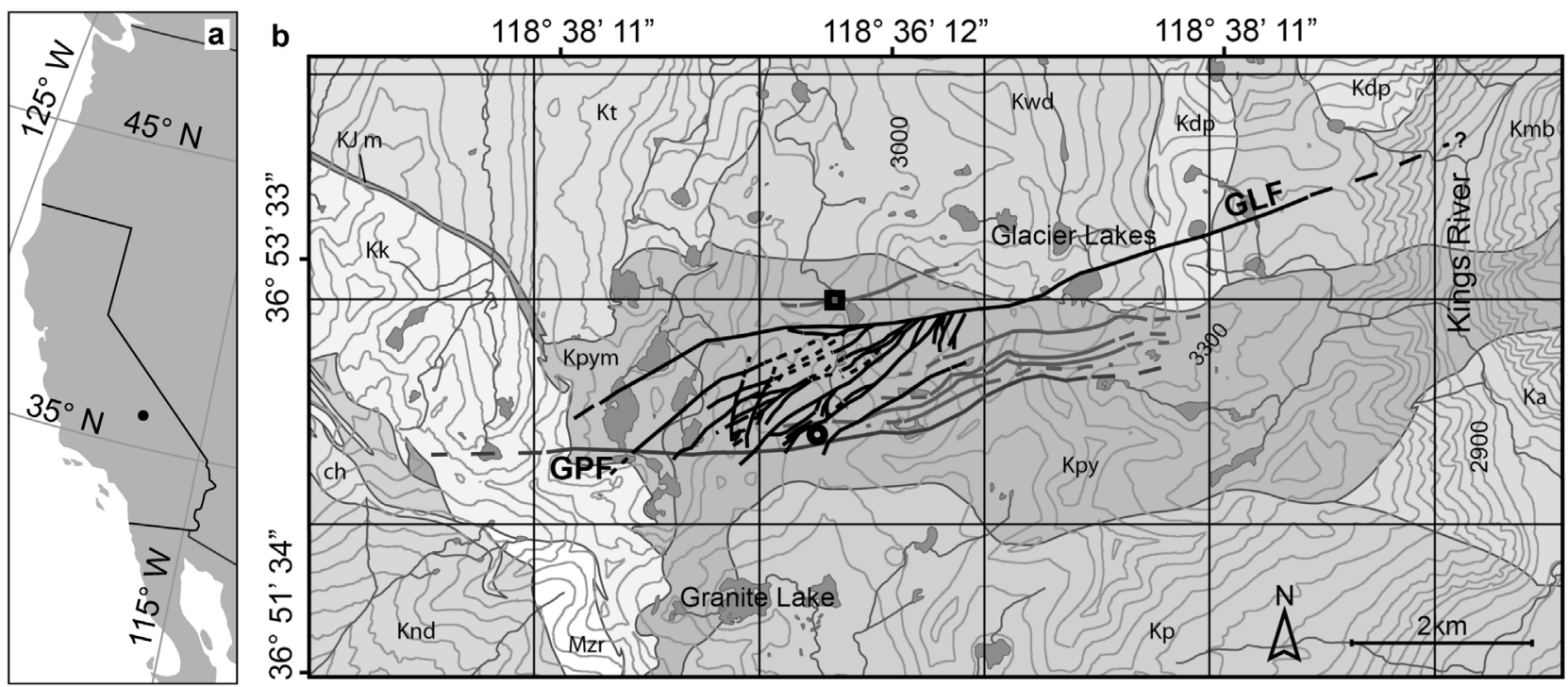

Figure 1. Location and geology of the Kings Canyon national park study area. (a) Map of western North America showing the location of the study area (black circle). (b) Map showing the distribution of faults. Black lines are the Glacier Lakes system (GLF), dark gray lines the Granite Pass fault (GPF) system [after Kirkpatrick et al., 2008]. Unit abbreviations are as follows: Kpy $=$ Pyramid pluton, Kpym $=$ Pyramid pluton mafic western facies, $\mathrm{Kk}=$ Granite of Kennedy Lakes, $\mathrm{Kjm}=$ mafic plutonic rock, $\mathrm{Kt}=$ Granite of Tehipite Dome, Kwd $=$ Granodiorite of White Divide, Knd = Granodiorite of North Dome, $\mathrm{ch}=$ calc-hornfels, $\mathrm{Mzr}=$ metarhyolite tuff, $\mathrm{Kp}=$ Paradise pluton, $\mathrm{Ka}=$ Arrow pluton, $\mathrm{Kmb}=$ Granodiorite of Muro Blanco, $\mathrm{Kdp}=$ Granite of Dougherty Peak [from Moore, 1978]. Open square is the location sampled for ${ }^{40} \mathrm{Ar} /{ }^{39} \mathrm{Ar}$ analysis, open circle shows the location of host rock samples for the $\mathrm{t}-\mathrm{T}$ analyses.

as pseudotachylytes are most often found in crystalline rocks [Sibson and Toy, 2006]. In contrast to pelitic rocks that form distinct equilibrium mineral assemblages over small variations in pressure and temperature [e.g., Yardley, 1989], felsic igneous rocks are less prone to react and therefore record less information about temperature and pressure conditions. At high pressures and temperatures some mineral assemblages within the pseudotachylytes or accompanying fault rocks can be used to estimate the depth at which pseudotachylytes were formed. For example, pseudotachylytes containing eclogite facies assemblages formed at depths in excess of $60 \mathrm{~km}$ [e.g., Austrheim and Boundy, 1994]. However, lower grade assemblages are less useful at pinpointing the depth of faulting within the upper $15 \mathrm{~km}$ of the seismogenic crust where the majority of earthquakes are observed to nucleate [Sibson, 1982]. Geochronological data can also be used to estimate depth if the exhumation rate since pseudotachylyte formation is constrained from independent evidence, allowing the depth to be found by dating the pseudotachylyte [Warr et al., 2007].

[5] In this study we use geochronological and thermochronological techniques to determine the depth at which pseudotachylytes in Kings Canyon national park, California were generated. The time at which the pseudotachylytes formed is found by precise ${ }^{40} \mathrm{Ar} /{ }^{39} \mathrm{Ar}$ dating of the pseudotachylyte matrix. A suite of low temperature thermochronometers are used to constrain the time-temperature history of the host rock granodiorite. Integrating the two data sets provides a quantitative assessment of the ambient temperature when the pseudotachylytes formed, and the corresponding depth assuming a typical geothermal gradient.
[6] As an example of the utility of these depth constraints, we pursue the implications for coseismic stress variability on the fault. Stress is commonly recognized to be highly variable on a fault. However, the amplitude and scale of variations requires observational constraints. Field observations show that the lengths of fault-parallel pseudotachylyte veins are limited to 1 to $10 \mathrm{~m}$ along strike. Coseismic slip consistent with the lengths of the generation surfaces would not dissipate sufficient energy as heat to melt the rock, so the patches must have formed as part of larger ruptures [Kirkpatrick and Shipton, 2009]. We use the depth constraint to estimate the stress at the initiation of slip and the subsequent stress changes associated with melt formation during the paleo-earthquake that formed the pseudotachylytes. Stress drop in the pseudotachylyte-bearing parts of the faults is found by estimating the shear resistance of the melt layers. This stress drop must represent the dynamic stress drop, and we show that the constraints on the magnitude of the stress change may also apply to the static stress drop. Comparison with seismologically observed macroscopic static stress drops quantitatively constrains the variation in stress drop between the pseudotachylyte and non-pseudotachylyte parts of the fault.

\section{Field and Microscope Observations of Pseudotachylyte-Bearing Faults}

[7] Pseudotachylyte-bearing faults in Kings Canyon national park, California, USA [Kirkpatrick et al., 2008, 2009], cut the Cretaceous Pyramid pluton granodiorite [Moore, 1978] (Figure 1) with mapped trace lengths of $\sim 1$ to $8 \mathrm{~km}$, and total apparent left-lateral strike-slip 

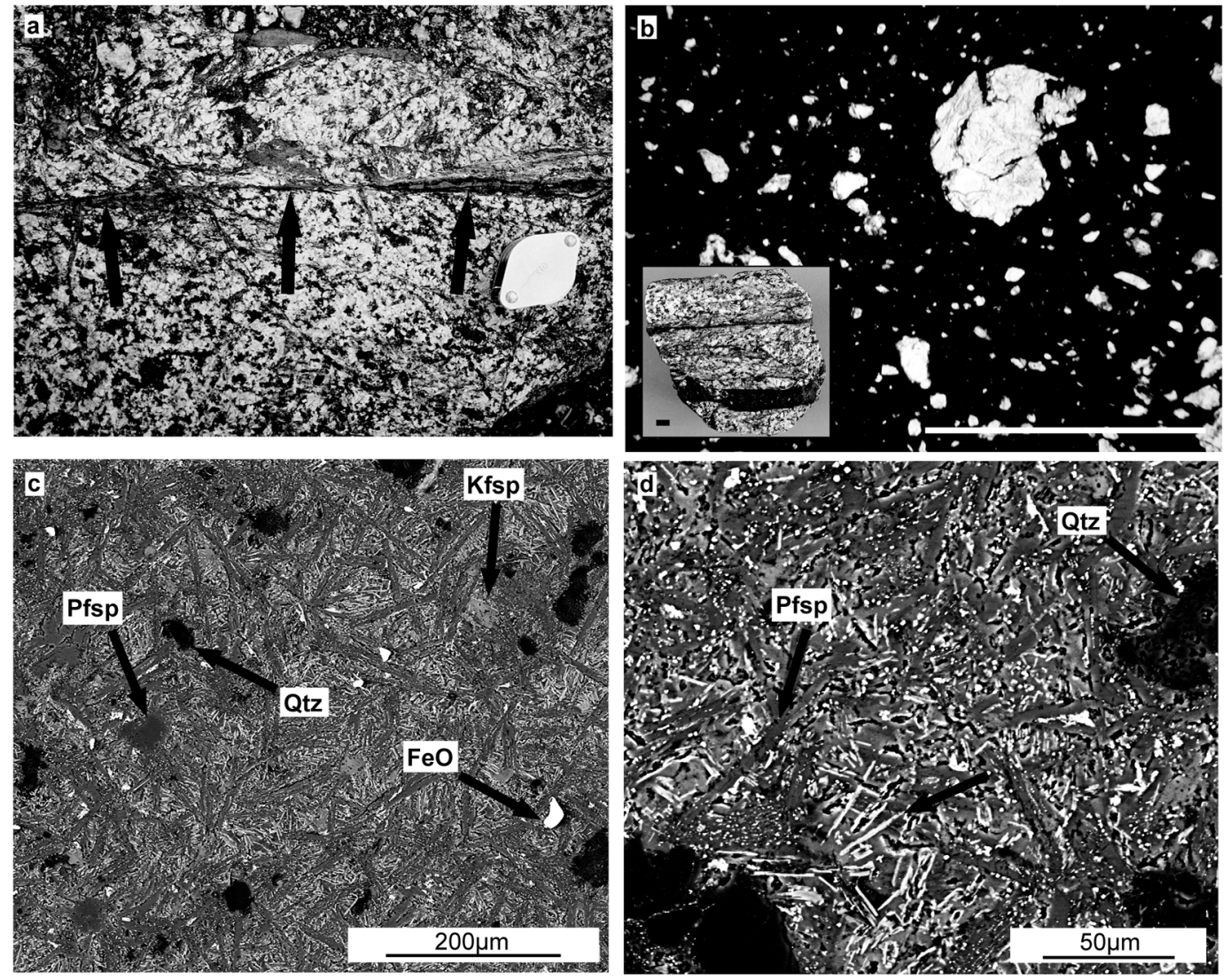

Figure 2. Pseudotachylytes in Kings Canyon national park. (a) Photograph of a narrow pseudotachylyte patch in the SKF. The fault-parallel vein (at the tips of the arrows) is banded and injection veins branch from the main fault vein at high angles. Hand lens for scale is $2.5 \mathrm{~cm}$ long. (b) Thin section photomicrograph (PPL, scale bar $1 \mathrm{~mm}$ ) of the sample dated with ${ }^{40} \mathrm{Ar} /{ }^{39} \mathrm{Ar}$. Inset shows the hand specimen prior to vein separation (scale bar $1 \mathrm{~mm}$ ). The pseudotachylyte contains rounded quartz and feldspar clasts dispersed in an isotropic matrix. (c) Scanning electron microscope backscattered electron (BSE) image of the same sample as in Figure $2 \mathrm{~b}$ showing the typical texture of the pseudotachylyte. Clasts of quartz (Qtz), Ca-rich plagioclase (Pfsp), orthoclase (Kfsp), titanite and Fe-oxides ( $\mathrm{FeO})$ are indicated. The matrix is made up of lath-shaped microcrystallites of plagioclase, indicative of quench textures that form as the melt rapidly cools. (d) Detail of the matrix of the pseudotachylyte showing the pristine nature of the samples. At the finest scale of observation, the material consists of interlocking microcrystallites of plagioclase and even finer microcrystallites that likely have a biotitic composition (arrow, no label), though this is difficult to verify with EDS spectra because they are finer than the spot size of the beam. Abbreviations the same as in Figure 2c.

offsets up to $\sim 80 \mathrm{~m}$. Slickenline orientations are predominantly sub-horizontal on each of the faults. Detailed fault rock descriptions and maps of fault rock distributions have previously been reported [Kirkpatrick et al., 2008, 2009; Kirkpatrick and Shipton, 2009]. We summarize here the key meso- and micro-structural characteristics of the pseudotachylytes significant to the present study.

[8] The Kings Canyon faults consist of multiple cataclastic fault cores within which fault-parallel pseudotachylyte veins form thin patches that are discontinuous along strike. The fault-parallel patches represent generation surfaces across which opposing sides of the fault moved relative to one another at seismic slip rates, resulting in melting [Sibson, 1975]. Centimeter-scale injection veins branch from the fault-parallel veins at high angles and contain the same aphanitic, gray to black, cohesive material with occasional rounded clasts of quartz and feldspar as the generation surfaces. Individual pseudotachylyte patches along the fault can be traced for $\sim 5$ to $10 \mathrm{~m}$ along strike. Where they terminate, the pseudotachylytes trend into cataclasites in which there is no evidence for melting [Kirkpatrick and Shipton, 2009]. The cataclasites along strike from the pseudotachylyte patches are made up of fragments of host rock quartz, feldspars, hornblende and biotite and clasts containing previously formed cataclasites. Epidote and chlorite are abundant in the matrix of the cataclasites. Fault cores and fractures containing chlorite and epidote are surrounded by alteration haloes containing sericitized feldspars and chloritized boitites and hornblende.

[9] Multiple pseudotachylyte patches are observed on three individual faults, and qualitative field observations suggest less than $20 \%$ of the total fault lengths contain 

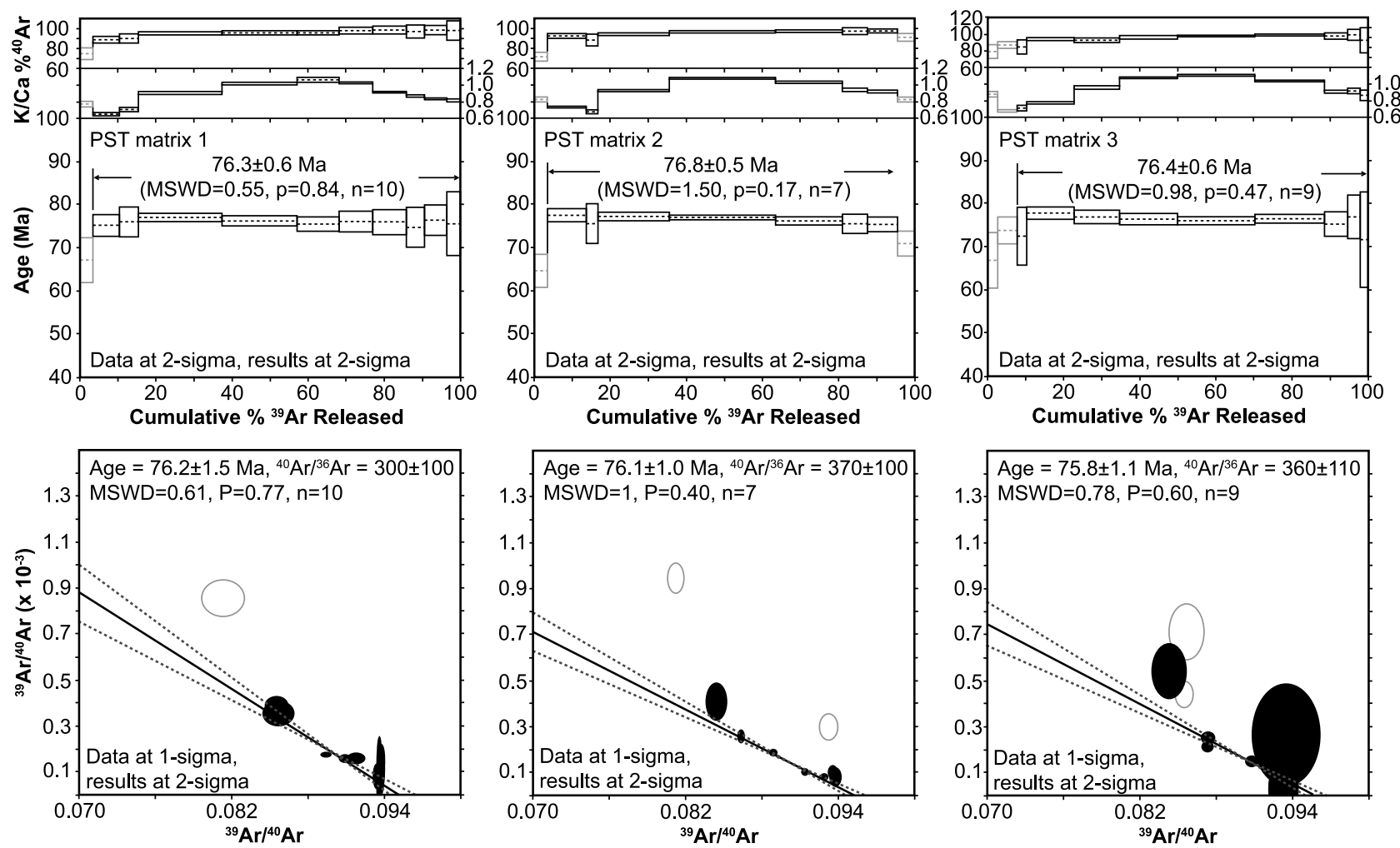

Figure 3. ${ }^{40} \mathrm{Ar} /{ }^{39} \mathrm{Ar}$ step heating spectra and isotope correlation plots for 3 aliquots of pseudotachylyte matrix. Gray points were rejected. Plateau calculations are based on the acceptance criteria of $n=3$ for the minimum number of contiguous steps with no resolvable slope, $\mathrm{F}=0.60$ (that is, $\geq 60 \%$ of ${ }^{39} \mathrm{Ar}$ released) and $\mathrm{P}=0.05$ for the probability of fit. All inverse isochron ages for all 3 aliquots overlap with the associated plateau and integrated ages showing the ${ }^{40} \mathrm{Ar} /{ }^{39} \mathrm{Ar}$ data to be robust. The ${ }^{40} \mathrm{Ar} /{ }^{36} \mathrm{Ar}$ trapped components all overlap with accepted atmospheric values [Nier, 1950].

pseudotachylyte [Kirkpatrick et al., 2009]. The fault-parallel pseudotachylyte patches are typically straight and $\leq 10 \mathrm{~mm}$ thick, although they locally reach $\sim 20 \mathrm{~mm}$ at geometrical irregularities such as jogs and steps. The pseudotachylytes are altered and replaced with epidote and chlorite to varying degrees. In pristine samples, the pseudotachylyte matrix contains microcrystallites that are tens to hundreds of $\mu \mathrm{m}$ long (Figure 2), indicative of quench textures [e.g., Philpotts, 1964] (see also the review by Magloughlin and Spray [1992]). Interlocking microcrystallites as small as $10 \mu \mathrm{m}$ long and $1 \mu \mathrm{m}$ wide make up the matrix in between the larger microcrystallites (Figure 2). Survivor clasts consisting of fragments of host rock minerals or previously formed cataclasites are typically rounded and range in size from $\sim 10 \mu \mathrm{m}$ to several $\mathrm{mm}$. Vesicles are not observed in any of the pseudotachylyte samples from the study area.

[10] We focus on pristine pseudotachylytes in the Skeeter fault (SKF), which displays the patchy geometry. In this fault, the pseudotachylytes crosscut all other cataclastic deformation textures in exposure and in thin section, indicating that they formed during the last slip event on the fault. Coseismic slip for ruptures with lengths equal to the patch dimensions $(0.1$ to $1 \mathrm{~mm}$, assuming static stress drop of 1 to $10 \mathrm{MPa}$ ) is insufficient to raise the temperature of the slip zone and overcome the latent heat of fusion to initiate melting even for extremely narrow slip zones [Griffith et al., 2008]. The discontinuous pseudotachylyte patches on the
SKF (as well as the other faults in the area) must therefore have formed in isolated patches over a rupture surface that was large compared to the 5 to $10 \mathrm{~m}$ long pseudotachylyte veins [Kirkpatrick and Shipton, 2009]. Empirical scaling relationships suggest that the largest earthquakes that could have occurred on the $1.4 \mathrm{~km}$ long SKF would have been $\sim \mathrm{M} 4$ if the entire fault had ruptured [Wells and Coppersmith, 1994]. Other pseudotachylyte-bearing faults in the study area, such as the Granite Pass fault [Kirkpatrick et al., 2008], are up to $\sim 8 \mathrm{~km}$ long and could have experienced a M5.8 earthquake.

\section{Age of Pseudotachylyte Generation From ${ }^{40} \mathrm{Ar} /{ }^{39} \mathrm{Ar}$ Analyses}

[11] The timing of pseudotachylyte generation was determined by high-precision ${ }^{40} \mathrm{Ar} /{ }^{39} \mathrm{Ar}$ dating of the pseudotachylyte matrix of a sample from the SKF. The heterogeneous nature of pseudotachylyte (Figure 2) makes bulk analyses challenging, and has led many recent studies to date pseudotachylyte by in situ ${ }^{40} \mathrm{Ar} /{ }^{39} \mathrm{Ar}$ dating techniques [e.g., Sherlock et al., 2008]. Although this allows linkage between petrographical observation and radioisotopic ages, it typically yields low-precision ages. To facilitate the determination of high-precision ages, we used a similar approach to Warr et al. [2007] and treated the pseudotachylyte samples as a phenocryst-rich basalt and 


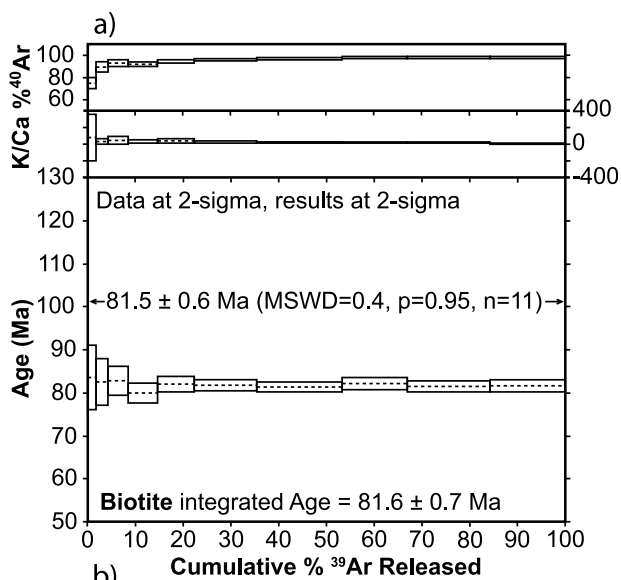

b) Cumulative $\%{ }^{39} \mathrm{Ar}$ Released

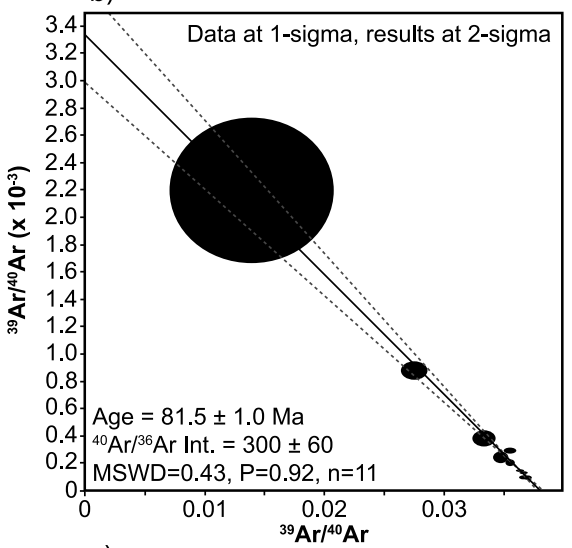

c)

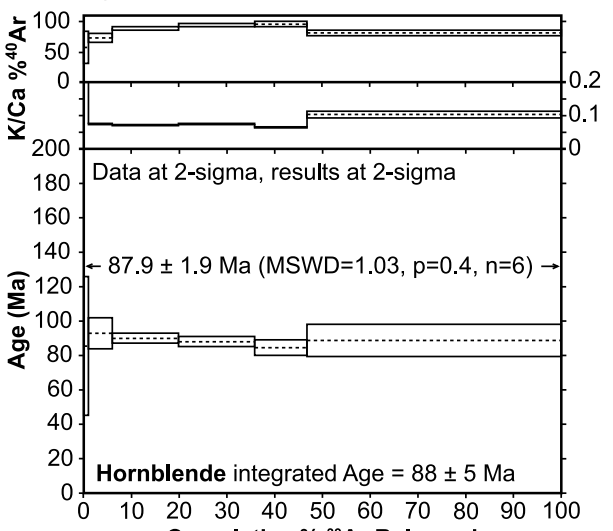

d) Cumulative $\%{ }^{39} \mathrm{Ar}$ Released

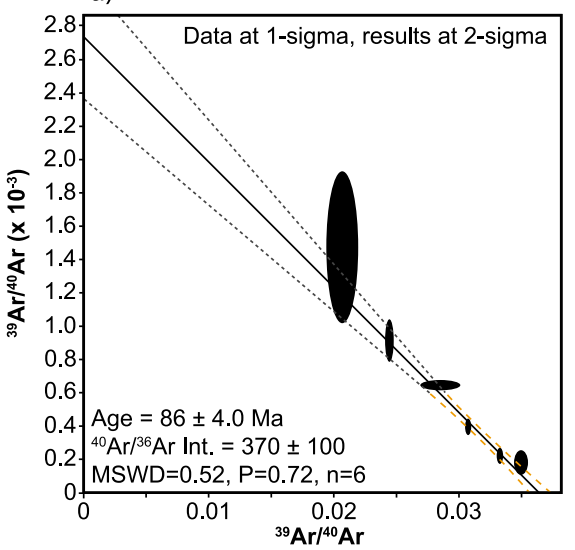

Figure 4. ${ }^{40} \mathrm{Ar} /{ }^{39} \mathrm{Ar}$ step heating spectra and isotope correlation plots for $(\mathrm{a}, \mathrm{b})$ biotite and $(\mathrm{c}, \mathrm{d})$ hornblende. step-heated three $6 \mathrm{mg}$ aliquots of pure pseudotachylyte matrix.

[12] Pseudotachylyte veins were separated from the host rock with a slow rotation diamond saw. The vein material was crushed and sieved $(63-125 \mu \mathrm{m})$. After magnetic separation and leaching in $\mathrm{HNO}_{3}$ and $\mathrm{HF}$, clast-free fragments of melt were handpicked under a binocular microscope to reduce the chance of including survivor clasts of wall rock or pre-existing fault rocks. The aliquots were loaded into $\mathrm{Cu}$ packets and irradiated in the McMaster reactor with international standards Fish Canyon Tuff sanidine (FCs, $28.201 \pm$ $0.023 \mathrm{Ma}$ [Kuiper et al., 2008], used for J-parameter measurements, $\mathrm{n}=60)$, GA1550 biotite $(98.8 \pm 0.5 \mathrm{Ma}$ [Renne et al., 1998]) and Taylor Creek Rhyolite sanidine (TCR-2s, $28.34 \pm 0.16 \mathrm{Ma}$ [Renne et al., 1998]). The ages for GA1550 and TCR-2s were determined relative to FCs and overlap with accepted values showing J-parameter measurements to be appropriate.

[13] Aliquots were step-heated using a 25-W Merchantek $\mathrm{CO}_{2}$ laser. Samples were heated for $20 \mathrm{~s}$ prior to $4.5 \mathrm{~min}$ cleanup. Extracted gases were cleaned using 2 GP50 SAES getters $\left(450^{\circ} \mathrm{C}\right.$ and room temperature) and a slush trap maintained at $-140^{\circ} \mathrm{F}$ using $\mathrm{CO}_{2}(\mathrm{~S})$ and acetone. Data were collected using an ARGUS multicollector mass spectrometer [Mark et al., 2009], and the BGC software package MassSpec was used for data regression and age calculations. Isotope data are corrected for blank, radioactive decay, mass discrimination and interfering reactions. ${ }^{40} \mathrm{Ar} /{ }^{39} \mathrm{Ar}$ ages also include error assigned to the J-parameter from the analysis of 30 monitors per sample. The atmospheric ratios of Nier [1950] were used to correct for mass discrimination and the decay constants of Steiger and Jäger [1977] were used for age calculations.

[14] All three aliquots of pseudotachylyte yielded concordant plateaux and the isotope correlation plots yielded inverse isochrons that overlap with the accepted atmospheric ${ }^{40} \mathrm{Ar} /{ }^{36} \mathrm{Ar}$ value [Nier, 1950] and show no evidence of excess ${ }^{40} \mathrm{Ar}$ (Figure 3, raw data are included in the auxiliary material). ${ }^{1}$ Data points excluded from the plateau calculations were excluded from inverse isochron calculations. The reproducibility of the same age 3 times with different aliquots is striking in comparison to previous attempts to date pseudotachylyte by similar methods [e.g., Di Vincenzo et al., 2004; Pennacchioni et al., 2006] and suggests that contamination by the host rock is negligible because it is unlikely the same amounts of contamination would have been included in the 3 different aliquots. Equally the data do not show evidence for ${ }^{37} \mathrm{Ar}$ or ${ }^{39} \mathrm{Ar}$ recoil. We interpret the isochron data as simple binary mixing lines between initial trapped components of atmospheric composition and $\mathrm{K}$ correlated radiogenic components whose ages overlap $(1 \sigma)$ with their associated plateau ages. The three ${ }^{40} \mathrm{Ar} /{ }^{39} \mathrm{Ar}$ ages clearly date the same event and yield a weighted mean age of $76.6 \pm 0.3 \mathrm{Ma}(2 \sigma)$ (Figure 3).

\section{Thermal Evolution of the Host Rock}

[15] To determine the depth at which the pseudotachylytes were formed, we used a suite of thermochronological data to

\footnotetext{
${ }^{1}$ Auxiliary materials are available in the HTML. doi:10.1029/ 2011JB008846
} 


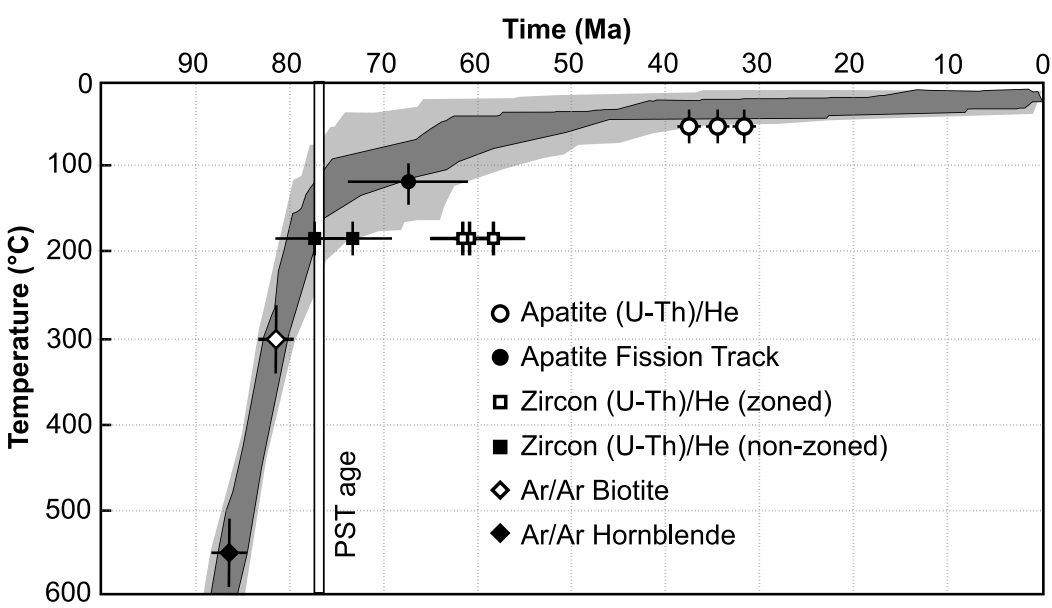

Figure 5. Thermal history of the pseudotachylyte-bearing Pyramid pluton (modern elevation $\sim 3000 \mathrm{~m}$ ). Time-temperature path derived from: closed diamond - hornblende ${ }^{40} \mathrm{Ar} /{ }^{39} \mathrm{Ar}(87.9 \pm 1.9 \mathrm{Ma}, 2 \sigma)$; open diamond - biotite ${ }^{40} \mathrm{Ar} /{ }^{39} \mathrm{Ar}(81.5 \pm 0.6 \mathrm{Ma}, 2 \sigma)$; closed and open squares - measured zircon $(\mathrm{U}-\mathrm{Th}) / \mathrm{He}$ ages; closed circle - apatite fission track $(67.2 \pm 6.6 \mathrm{Ma}, 2 \sigma$, mean track length of $13.96 \pm 1.15 \mu \mathrm{m})$; and open circles - measured apatite $(\mathrm{U}-\mathrm{Th}) / \mathrm{He}$ ages (mean age $=34.5 \pm 3.8 \mathrm{Ma}, 2 \sigma$ ). Individual (U-Th)/He ages shown with $2 \sigma$ uncertainty based on the reproducibility of the Durango (apatite, $6 \%$ ) and Fish Canyon (zircon, 12\%) age standards. The bimodal zircon age population is consistent with the observed zonation, with the younger population experiencing higher fractional He loss from the $\mathrm{U}$ enriched rims. Inverse modeling from thermochronological data performed using HeFTy [Ketcham, 2005] using the ${ }^{40} \mathrm{Ar} /{ }^{39} \mathrm{Ar}$ ages to define the high temperature portion of the time-temperature curve, and the permitted time-Temperature path envelope shown as dark gray (50\% confidence interval) and mid gray $(95 \%$ confidence interval) zones. Model uses $\mathrm{U}_{\text {rim }} / \mathrm{U}_{\text {core }}=20$ for the zoned zircon population (younger age population).

constrain the post emplacement time-temperature $(t-T)$ path of the host granodiorite. ${ }^{40} \mathrm{Ar} /{ }^{39} \mathrm{Ar}$ (hornblende and biotite), zircon $(\mathrm{U}-\mathrm{Th}) / \mathrm{He}(\mathrm{ZHe})$, apatite fission track (AFT) and apatite $(\mathrm{U}-\mathrm{Th}) / \mathrm{He}(\mathrm{AHe})$ analyses are used to reconstruct the cooling history from $\sim 550$ to $60^{\circ} \mathrm{C}$. Ages were determined from samples collected 100-200 $\mathrm{m}$ from mapped fault traces at the same elevations at which the pseudotachylyte-bearing faults are exposed $(\sim 3000 \mathrm{~m}$, see Figure 1).

[16] Single crystals of biotite and hornblende were harvested from crushed granodiorite using magnetic separation and handpicking under binocular microscope. Crystals were washed in DI and methanol, and analyzed alongside the pseudotachylyte aliquots using the standard methodologies. The single crystal aliquots yielded age spectra and integrated ages within uncertainty of each other indicating a ${ }^{40} \mathrm{Ar} /{ }^{39} \mathrm{Ar}$ hornblende age of $87.9 \pm 1.9 \mathrm{Ma}(2 \sigma)$, while the single crystal biotite aliquot yielded an age of $81.5 \pm 0.6 \mathrm{Ma}(2 \sigma)$, (Figure 4, data are included in the auxiliary material).

[17] Inclusion- and defect-free apatite and zircon crystals were hand-picked and each crystal loaded into a Pt foil tubes for (U-Th)/He analyses. ${ }^{4} \mathrm{He}$ was determined by peak height comparison using a Hiden HAL3 spectrometer [Foeken et al., 2006]. After degassing, the apatites were dissolved using standard techniques [Persano et al., 2007] and the

Table 1. (U-Th)/He Data Used to Constrain the $t-T$ Path of the Pyramid Pluton ${ }^{\mathrm{a}}$

\begin{tabular}{|c|c|c|c|c|c|c|c|}
\hline Sample & ${ }^{4} \mathrm{He}(\mathrm{ncc})$ & ${ }^{238} \mathrm{U}$ (ng) & ${ }^{232} \mathrm{Th}$ (ng) & $\mathrm{Th} / \mathrm{U}$ & Measured Age (Ma) & $\mathrm{F}_{\mathrm{T}}$ & Corrected Age (Ma) \\
\hline \multicolumn{8}{|c|}{ Apatite } \\
\hline KCVa-1 & 0.28 & 0.04 & 0.10 & 2.41 & 37.2 & 0.66 & 56.5 \\
\hline $\mathrm{KCVa}-2$ & 0.16 & 0.03 & 0.06 & 2.41 & 31.6 & 0.57 & 54.0 \\
\hline KCVa-3 & 0.25 & 0.04 & 0.09 & 2.52 & 34.8 & 0.69 & 50.7 \\
\hline \multicolumn{8}{|c|}{ Zircon } \\
\hline $\mathrm{KCVz}-1$ & 16.31 & 1.31 & 1.73 & 1.31 & 77.5 & 0.75 & 104.0 \\
\hline $\mathrm{KCVz}-2$ & 24.07 & 2.72 & 2.79 & 1.02 & 58.3 & $0.72 *$ & 80.5 \\
\hline $\mathrm{KCVz}-3$ & 12.97 & 1.16 & 1.21 & 1.04 & 73.4 & 0.73 & 100.1 \\
\hline $\mathrm{KCVz}-4$ & 2.45 & 0.26 & 0.31 & 1.20 & 60.8 & $0.68^{*}$ & 89.6 \\
\hline $\mathrm{KCVZ}-5$ & 7.87 & 0.84 & 0.87 & 1.04 & 61.4 & 0.65 & 94.3 \\
\hline
\end{tabular}

${ }^{\mathrm{a}} \mathrm{All}$ analyses are of single crystal aliquots. For zircon analyses total analytical uncertainty is $<3 \%$ for apatite $<2 \%$. $\mathrm{F}_{\mathrm{T}}$ corrections are calculated after [Farley et al., 1996] and [Hourigan et al., 2005] assuming homogeneous U and Th distribution. ZHe ages fall into two groups, reflecting the strong relative rim enrichment in $U$ observed in $\sim 40 \%$ of the zircon population using CL and fission track density variations (see the auxiliary material for detailed analysis). The remaining zircons exhibited $\mathrm{CL}$ zonation consistent with approximately homogeneous $\mathrm{U}$ distribution. $\mathrm{F}_{\mathrm{T}}$ correction is therefore not valid for $\sim 50 \%$ of crystals. Inverse modeling was performed using the uncorrected (U-Th)/He ages (apatite and zircon) and step function zonation patterns (see text for details). 
Table 2. Apatite Fission Track Data Used to Constrain the $t$-T Path of the Pyramid Pluton ${ }^{\text {a }}$

\begin{tabular}{cccccccccccc}
\hline $\mathrm{c}$ & $\begin{array}{c}\text { Number of } \\
\text { Crystals }\end{array}$ & $\begin{array}{c}\rho_{\mathrm{s}} \\
\left(\times 10^{5} \mathrm{~cm}^{-2}\right)\end{array}$ & $\mathrm{N}_{\mathrm{s}}$ & $\begin{array}{c}\rho_{\mathrm{i}} \\
\left(\times 10^{5} \mathrm{~cm}^{-2}\right)\end{array}$ & $\mathrm{N}_{\mathrm{i}}$ & $\begin{array}{c}\rho_{\mathrm{D}} \\
\left(\times 10^{5} \mathrm{~cm}^{-2}\right)\end{array}$ & $\mathrm{N}_{\mathrm{D}}$ & $\mathrm{P}\left(\chi^{2}\right)$ & Age & Dpar $(\mu \mathrm{m})$ & MTL $(\mu \mathrm{m})$ \\
\hline GPP3 & 30 & 19.68 & 1474 & 72.93 & 5463 & 18.08 & 5088 & 74 & $67.2 \pm 3.3$ & $2.40 \pm 0.30$ & $13.96 \pm 1.15[62]$ \\
\hline
\end{tabular}

${ }^{a}$ Analyses by external detector method with dosimeter IRMM540 and $\zeta=277 \pm 9$ [Hurford and Green, 1983]. Fission tracks were revealed by etching in $5.5 \mathrm{M} \mathrm{HNO}_{3}$ for $20 \mathrm{~s}$ at $21^{\circ} \mathrm{C}$. $\rho_{\mathrm{s}}$ - spontaneous track density, $\mathrm{N}_{\mathrm{s}}$ - number of spontaneous tracks, $\rho_{\mathrm{i}}$ - induced track density, $\mathrm{N}_{\mathrm{i}}-$ number of induced tracks, $\rho_{\mathrm{D}}$ - track density of dosimiter, $\mathrm{N}_{\mathrm{D}}$ - number of tracks from dosimiter, $\mathrm{P}\left(\chi^{2}\right)$ - chi squared probability that all single-crystal ages represent a single population, Dpar - mean diameter of fission track etch pits used to assess the composition of the apatites. MTL = mean track length, value in the bracket is the number measured.

zircons by Parr bomb acid digestion after Dobson et al. [2009]. U and Th determinations were made by isotopic dilution on an Agilent X ICP-MS.

[18] Zonation of $U$ and Th in zircon is often highly variable, and can cause significant differences in the (U-Th)/He ages between individual crystals. SEM cathodoluminescence (CL) imaging was used to assess $U$ and Th zonation in the zircon crystal population [Dobson et al., 2008] (details are included in the auxiliary material). Inverse correlation of the CL intensity and the U concentration was confirmed using zircons included in the fission track mount. Approximately $20 \%$ of the zircon population exhibited essentially homogeneous CL zonation, and a further $40 \%$ showed narrow oscillatory zonation over the majority of the crystal volume. The narrow oscillatory CL zonation can be approximated by a homogeneous $U$ concentration profile on the scale of He ejection [Hourigan et al., 2005; Dobson et al., 2008], and $U$ and Th zonation will have minimal effect on the zircon (U-Th)/He ages of $\sim 60 \%$ of the population. The remaining $40 \%$ of the zircon population have a narrow 5-20 $\mu \mathrm{m}$ rim of extremely low (zero) CL intensity and $\mathrm{U}_{\text {rim }} / \mathrm{U}_{\text {core }} \gg 10$. U rich rims cause an increased fractional loss of He by alpha-ejection, and zircon (U-Th)/He ages determined on these crystals will be significantly $(\sim 10$ $20 \%$ ) younger than those from the effectively homogenous population [Dobson et al., 2008].

[19] The zircon (U-Th)/He ages fall into two groups at 58$62 \mathrm{Ma}$ and 73-78 $\mathrm{Ma}$ (Figure 5 and Table 1). The zonation observed in the sample suggests that the younger population correspond to crystals with strong relative rim enrichment in $U$, and the older population correspond to crystals that exhibit CL zonation consistent with approximately homogeneous $\mathrm{U}$ distribution. Three apatite $(\mathrm{U}-\mathrm{Th}) / \mathrm{He}$ ages ranged from 31.6 to $37.2 \mathrm{Ma}$ with a mean of $53.8 \pm 5.9 \mathrm{Ma}$ (Table 1).

[20] Apatite fission tracks were revealed by etching in $5.5 \mathrm{M} \mathrm{HNO}_{3}$ for $20 \mathrm{~s}$ at $21^{\circ} \mathrm{C}$, and the compositional control on annealing was monitored using Dpar (Table 2). The sample yielded AFT age of $67.2 \pm 6.6 \mathrm{Ma}(2 \sigma)$, a mean track length of $13.96 \pm 1.15 \mu \mathrm{m}(2 \sigma, \mathrm{n}=62)$, and a mean apatite (U-Th)/He age of $34.5 \pm 2.8 \mathrm{Ma}(2 \sigma, \mathrm{n}=3)$ (Figure 5, Tables 1 and 2).

\section{Depth of Faulting}

[21] Inverse modeling of the thermochronology data from the host rock was performed using HeFTy [Ketcham, 2005], using all the available ${ }^{40} \mathrm{Ar} /{ }^{39} \mathrm{Ar}$, (U-Th)/He and fission track data described above to provide the constraints on the model [Reiners et al., 2004; Dobson et al., 2010]. The younger (zoned) population of zircon (U-Th)/He ages was modeled, using concentration profiles based on the CL images $5 \times, 10 \times, 20 \times$ and $50 \times$ rim enrichment [after Dobson et al., 2008]. Figure 5 shows the $t-T$ path envelope for crystals with $20 \times$ rim enrichment, which appears to be a minimum estimate of core-rim enrichment based on the observed track densities. For all modeled concentration changes, the form of the $t$ - $T$ history envelope was unchanged but at lower levels of enrichment $(5 \times)$ the temperature at which the system shifts from rapid to slow cooling increases by $\sim 20^{\circ} \mathrm{C}$. In all instances, the $t-T$ histories support rapid ( $\sim 40^{\circ} \mathrm{C} / \mathrm{Myr}$ ) cooling to $<150^{\circ} \mathrm{C}$ by $80-75 \mathrm{Ma}$ as the pluton was rapidly exhumed to a few kilometers depth immediately after intrusion (Figure 5). Subsequent slower cooling rates (average $<10^{\circ} \mathrm{C} / \mathrm{Myr}$ ) from $70 \mathrm{Ma}$ to the present reflect the general tectonic quiescence during the Paleogene [House et al., 2001].

[22] Integrating the high precision pseudotachylyte formation age with the host rock $t-T$ history (Figure 5) shows that the ambient temperature at the time of SKF pseudotachylyte formation was between $\sim 110$ and $\sim 160^{\circ} \mathrm{C}$. The corresponding depth at those temperatures is a function of the geothermal gradient. Modern volcanic arcs have geothermal gradients exceeding $40^{\circ} \mathrm{C} / \mathrm{km}$ [Rothstein and Manning, 2003], which would imply depths of 2.4 to $3.6 \mathrm{~km}$. However, pluton emplacement in the Sierra terminated at $\sim 80 \mathrm{Ma}$, as subduction shallowed and migrated eastward. The associated crustal thickening is thought to have reduced the geothermal gradient rapidly [Dumitru, 1990]. Our thermochronological data indicate rapid cooling prior to $\sim 75 \mathrm{Ma}\left(>40^{\circ} \mathrm{C} / \mathrm{Ma}\right)$, with much lower cooling rates through the Cenozoic (generally $<7^{\circ} \mathrm{C} / \mathrm{Ma}$ ). This is consistent with rapid readjustment of the geothermal gradient, synchronous with the exhumation of the pseudotachylytebearing rocks to within a few kilometers of the surface, by $\sim 60 \mathrm{Ma}$. At the time of pseudotachylyte generation the geothermal gradient is likely to have been 25 to $30^{\circ} \mathrm{C} / \mathrm{km}$ [House et al., 2001; Clark et al., 2005] implying rupture depths of $\sim 3.2$ to $5.8 \mathrm{~km}$. While the inverse modeling supports a temperature of $110-160^{\circ} \mathrm{C}$ at $\sim 77 \mathrm{Ma}$ (time of pseudotachylyte formation), it is possible that the ambient temperatures at the time of faulting were higher (a maximum of $\sim 220^{\circ} \mathrm{C}$ is also allowed by the model). However, the very rapid initial cooling followed by much slower subsequent cooling indicates that exhumation-derived cooling and the relaxation of the geothermal gradient were synchronous. This implies that if ambient temperatures at the time of pseudotachylyte formation were higher they were likely accompanied by a higher geothermal gradient and the depth of pseudotachylyte formation would still be within our calculated range. In the following analysis, we will consider the implications for pseudotachylyte generation in the depth 
Table 3. Composition of Solidified Pseudotachylyte Measured by Wavelength Dispersive Sequential X-ray Fluorescence (WD-XRF) Equivalent to a Trachyandesite

\begin{tabular}{lc}
\hline Oxides & Wt \% \\
\hline $\mathrm{SiO}_{2}$ & 57.88 \\
$\mathrm{Al}_{2} \mathrm{O}_{3}$ & 16.28 \\
$\mathrm{Fe}_{2} \mathrm{O}_{3}$ & 7.08 \\
$\mathrm{MgO}$ & 3.41 \\
$\mathrm{CaO}$ & 4.81 \\
$\mathrm{Na}$ & 3.20 \\
$\mathrm{~K}_{2} \mathrm{O}$ & 3.87 \\
$\mathrm{TiO}_{2}$ & 0.95 \\
$\mathrm{MnO}$ & 0.11 \\
$\mathrm{P}_{2} \mathrm{O}_{5}$ & 0.28 \\
$\mathrm{LOI}$ & 1.81 \\
Total & $\mathbf{9 9 . 6 8}$ \\
\hline
\end{tabular}

range $2.4 \mathrm{~km}$ (minimum depth at $40^{\circ} \mathrm{C} / \mathrm{km}$ ) to $6.0 \mathrm{~km}$ (maximum depth at $25^{\circ} \mathrm{C} / \mathrm{km}$ ).

\section{Melt Shear Resistance}

[23] Following melting, the rheology of the slip zone transitions from sliding across a frictional contact to shearing of a viscous fluid in a layer between the wall rocks [Jeffreys, 1942; Fialko and Khazan, 2005]. Shear resistance in the melt layer is a complex function of melt viscosity, slip velocity and shear localization, which are all dependent on temperature and the duration of shearing [Fialko and Khazan, 2005; Nielsen et al., 2008, 2010a]. However, assuming a constant velocity gradient in the melt layer, the relationship between shear stress $\sigma_{m}(\mathrm{~Pa})$, slip velocity $U_{o}$ $(\mathrm{m} / \mathrm{s})$, slip zone thickness $H(\mathrm{~m})$ and melt viscosity $\eta(\mathrm{Pa} \mathrm{s})$ can be approximated as

$$
\sigma_{m}=\eta \frac{U_{o}}{H}
$$

The shear resistance of the melt can therefore be estimated because slip zone thickness is measured in the field and in thin section, and slip velocity can be assumed to have been of the order of $1 \mathrm{~m} / \mathrm{s}$ [Spray, 1993; Ujiie et al., 2007]. The viscosity of pseudotachylyte melts is controlled by melt composition, clast content and temperature, which must all be measured for reliable estimates of $\eta$.

[24] The pseudotachylyte composition was determined using wavelength dispersive sequential X-ray fluorescence (Table 3). Clast content and clast compositions were measured from SEM backscattered electron (BSE) images based on the gray scale value of each pixel (see Figure 2) following the method of Bjørk et al. [2009] (cf. Ray [1999] and Di Toro and Pennacchioni [2004]). Mineral phases that correspond to each gray scale value were determined using integrated energy dispersive X-ray (EDX). The area of pseudotachylyte analyzed was maximized using a mosaic of BSE images taken at the same magnification $(\times 250)$ and image capture conditions (brightness and contrast). Most clasts were fragments of cataclasite containing multiple mineral phases (Table 4). Mineral phases identified in monocrystal clasts were limited to quartz, Ca-rich plagioclase, orthoclase, Fe-oxides and titanite. Microcrystallites in the pseudotachylyte matrix have a composition similar to plagioclase making it difficult to distinguish many of the clasts from the matrix based on gray scale value alone, so clast identification was completed manually. The minimum clast size that can be identified at the magnification is $\sim 15$ $\mu \mathrm{m}$, though small clasts are likely under-sampled as they are difficult to distinguish from the texturally complex matrix. The pseudotachylyte sample used for ${ }^{40} \mathrm{Ar} /{ }^{39} \mathrm{Ar}$ dating has a clast content of $\sim 13.5 \%$.

[25] Peak temperature in the melt phase was determined from the survivor clast compositions [Spray, 1992, 2010]. The dominance of quartz, and prevalence of Ca-rich plagioclase feldspars over Na-rich plagioclase in the clast population is consistent with peak temperatures in excess of $1100^{\circ} \mathrm{C}$, but the preservation of plagioclase requires temperatures not far in excess of $1150^{\circ} \mathrm{C}$. The absence of pseudotachylyte partitioning into spherulitic and microlitic domains corroborates melt temperatures $<1450^{\circ} \mathrm{C}$ [Di Toro and Pennacchioni, 2004], which is used in the viscosity calculation as an upper bound on temperature.

[26] Melt viscosities were calculated using Conflow [Mastin and Ghiorso, 2000; Mastin, 2002] which calculates the melt viscosity using the Shaw [1972] model for magmas with silica content less than $70 \mathrm{wt} \%$ by implementing the MELTS algorithm [Ghiorso and Sack, 1995] using a compilation of lab values for the thermodynamic properties. The effect of crystal content on the viscosity is incorporated using the Einstein-Roscoe equation [Marsh, 1981]. For the SKF melt composition, clast content and temperature under lithostatic stresses of 77 to $182 \mathrm{MPa}$ and maximum water content bounded by the XRF LOI, melt viscosities $(\eta)$ would be in the order of 10 to $310 \mathrm{~Pa} \mathrm{~s}$. Similar values for melt viscosity have been reported previously from a variety of pseudotachylyte faults [Spray, 1993; Ujiie et al., 2007].

[27] The low viscosities and order of magnitude variation are a direct result of the high temperatures inferred for the melt phase and the strong temperature dependence of the viscosity. In addition, the small amount of dissolved water inferred from the XRF LOI $(\sim 2 \%)$ is sufficient to decrease viscosity by many orders of magnitude, contributing to the low values [e.g., Spray, 1993; Hess and Dingwell, 1996]. Our viscosity estimates assume Newtonian behavior for the bulk melt phase, which is unlikely given the melt contains suspended clasts. Our microstructural analyses show the pseudotachylyte has only $13.5 \%$ clasts so the effects of nonNewtonian behavior resulting from both clast content [Mueller et al., 2010] and clast shape [Mueller et al., 2011]

Table 4. Image Analysis Results of Measurements of Clast Content and Composition ${ }^{\mathrm{a}}$

\begin{tabular}{lcc}
\hline & Number of Clasts & Area of Clasts (pixels) \\
\hline Original image & $\mathrm{n} / \mathrm{a}$ & 7086228 \\
Quartz & $326(48.5)$ & $395230(5.6)$ \\
Mixed grains & $47(7.0)$ & $366900(5.2)$ \\
Plagioclase & $228(33.9)$ & $160695(2.3)$ \\
Albite & $4(0.6)$ & $4426(0.06)$ \\
Titanite/Fe-oxides & $67(10.0)$ & $29011(0.4)$ \\
Total grain values & $672(100)$ & $956262(13.56)$ \\
Matrix & $\mathrm{n} / \mathrm{a}$ & $6104080(86.44)$ \\
\hline
\end{tabular}

${ }^{a}$ Results show the abundance of major mineral phases and mixed grains as proportion of total number of clasts identified and proportion of total area of clasts. Values in parentheses are percentages. 
would have a negligible effect on bulk viscosity at the high strain rates characteristic of seismic slip rates.

[28] Using the calculated viscosities, typical slip velocities $(1 \mathrm{~m} / \mathrm{s})$ and the observed thickness of the pseudotachylyte veins $(0.25-10 \mathrm{~mm})$, equation (1) shows that $\sigma_{\mathrm{m}}$ ranges from $\sim 0.04$ to $0.12 \mathrm{MPa}\left(\mathrm{T}=1100^{\circ} \mathrm{C}, \eta=310 \mathrm{~Pa} \mathrm{~s}\right)$ and $\sim 0.001$ to $0.04 \mathrm{MPa}\left(\mathrm{T}=1450^{\circ} \mathrm{C}, \eta=10\right)$. Higher slip velocities do not alter the results significantly. These values of $\sigma_{\mathrm{m}}$ are comparable with those estimated from other seismogenic faults [Ujiie et al., 2007; Brodsky et al., 2009]. Low shear resistance is consistent with low shear:normal stress ratios calculated from temperature measurements in boreholes drilled into seismically active faults [Kano et al., 2006] and also with high velocity rock friction experiments in which melting of crystalline rock samples at near seismogenic conditions results in very low shear resistance [Di Toro et al., 2006; Niemeijer et al., 2011]. Additionally, theoretical models of shear resistance in the presence of melt consistently demonstrate that the presence of melt lubricates a fault, even in the case of thin melt layers partly supported by solidsolid asperity contacts [Nielsen et al., 2010a, 2010b].

\section{Discussion}

\subsection{Temperature and Depth of Pseudotachylyte Generation}

[29] We have combined ${ }^{40} \mathrm{Ar} /{ }^{39} \mathrm{Ar}$ dating of the pseudotachylyte in the SKF with the temperature-time history of the host rock to constrain the depth at which the pseudotachylyte formed. The thermal history indicates that the ambient temperature in the country rock at the time of pseudotachylyte formation was $110-160^{\circ} \mathrm{C}$, implying that the depth at which the pseudotachylytes formed was less than $6 \mathrm{~km}$. The compilation of pseudotachylyte reports in the literature by Sibson and Toy [2006] shows that 2.4 to $6 \mathrm{~km}$ is relatively shallow for pseudotachylyte formation, but not exceptional.

[30] Pseudotachylyte formation was accompanied by the formation of epidote and chlorite in adjacent cataclasites, and some pseudotachylytes are altered to chlorite. Mineral assemblages containing predominantly chlorite and epidote, similar to those associated with the faults we describe, have previously been interpreted as representative of depths of faulting between 8 and $11 \mathrm{~km}$ in both the Sierra Nevada [Pachell and Evans, 2002; Griffith et al., 2008] and the Adamello batholith, Italy [e.g., Di Toro and Pennacchioni, 2004]. Even in the absence of actinolite, chlorite and epidote assemblages are typically inferred to represent temperatures of 250 to $300^{\circ} \mathrm{C}$ [e.g., Guilbert and Park, 1986; Yardley, 1989], consistent with fluid inclusion constraints [Bruhn et al., 1994]. Epidote-chlorite assemblages may also form at lower temperatures, and are reported from prehnitepumpellyite facies conditions [Yardley, 1989]. However, the study area faults lack other low temperature minerals (e.g., zeolites), so the fault rock assemblage likely formed in excess of $250^{\circ} \mathrm{C}$.

[31] The chlorite and epidote assemblage we describe is strictly limited to within faults, fractures and veins. Alteration halos accompany all of the mineralized features, defined by the hydrous alteration of plagioclase to sericite and horblende and biotite to chlorite. Regionally, the primary igneous mineral assemblage is intact, and the bulk composition of the granodiorite is not altered. Hydrothermal fluids focused in the faults and fractures therefore drove the chlorite-epidote mineralization; these minerals formed because of the presence of those fluids. Under these conditions externally buffered fluids controlled the composition of the alteration assemblage, and the temperature inferred from the hydrothermal assemblage reflects the fluid temperature.

[32] Our data show that advecting hydrothermal fluids passing through the faults were hotter than the surrounding rock. The thermochronology shows the host rock was at $110-160^{\circ} \mathrm{C}$, whereas the hydrothermal mineral assemblage indicates the fluid temperature was probably greater than $250^{\circ} \mathrm{C}$. The thermochronology does allow for ambient rock temperatures up to $220^{\circ} \mathrm{C}$, suggesting the temperature difference between the rock and hydrothermal fluid could have been relatively small. However, the observation of hot hydrothermal fluids compared to the surrounding rock is consistent with temperatures associated with epidote and chlorite mineralization measured in geothermal systems that reach several hundreds of degrees at depths of $<1 \mathrm{~km}$ [e.g., Bird and Spieler, 2004, and references therein]. Exhumed hydrothermal systems show epidote and chlorite precipitating at paleo-depths of less than $4 \mathrm{~km}$ around granitic intrusions [e.g., Dilles and Einaudi, 1992] so hydrothermal assemblages forming at temperatures greater than would be predicted from geothermal gradients are observed. Anomalously high temperature fluids are characteristic of hydrothermal systems in and around intrusive bodies. It follows that hydrothermal mineral assemblages may indicate temperatures that are significantly different to the surrounding country rock and inferring the ambient temperature at the time of faulting from hydrothermal assemblages is problematic.

\subsection{Stress Drop Variability}

[33] The depth constraints provide information regarding the stress on the fault at the initiation of slip. The resolved shear stress resulting in failure on the fault at the time of rupture nucleation, $\sigma_{0}$, can be calculated by assuming the intermediate principal stress, $\sigma_{2}$, was vertical, consistent with the strike-slip offset across the SKF and other study area faults [Sibson, 1974]. For an average rock density of $2800 \mathrm{~kg} / \mathrm{m}^{3}$, rupture depths of 2.4 and $6 \mathrm{~km}$ equate to lithostatic stresses of $66 \mathrm{MPa}$ and $165 \mathrm{MPa}$, respectively. Failure of optimally oriented strike-slip faults at these depths with $\sigma_{2}$ equal to the lithostatic stress, setting $\sigma_{2}$ equal to the mean of $\sigma_{1}$ an $\sigma_{3}$ (following Sibson [1974]), Byerlee friction of 0.75 and hydrostatic pore pressures, requires $\sigma_{0}$ to be 21-51 MPa [Sibson, 1974, 1985].

[34] The failure stress values are several orders of magnitude greater than the shear resistance of the pseudotachylyte fault veins estimated in Section 6. Assuming uniform failure stress, $\sigma_{0}$, stress drop in the pseudotachylyte-bearing parts of the fault, $\Delta \sigma_{\mathrm{m}}$, is given by $\sigma_{0}-\sigma_{\mathrm{m}}$. Because the resisting stress in the pseudotachylyte-bearing parts of the fault is negligible (for all possible depths and melt temperatures), $\Delta \sigma_{\mathrm{m}}$ is the same magnitude as the static failure stresses (21$51 \mathrm{MPa}$ ). These results suggest that the stress drop over those patches of the faults that melted was complete, which is in agreement with theoretical expectations [Fialko and Khazan, 2005; Nielsen et al., 2008]. Pore pressures exceeding hydrostatic values at the initiation of slip could have reduced $\sigma_{0}$, and consequently $\Delta \sigma_{\mathrm{m}}$ but there is no 


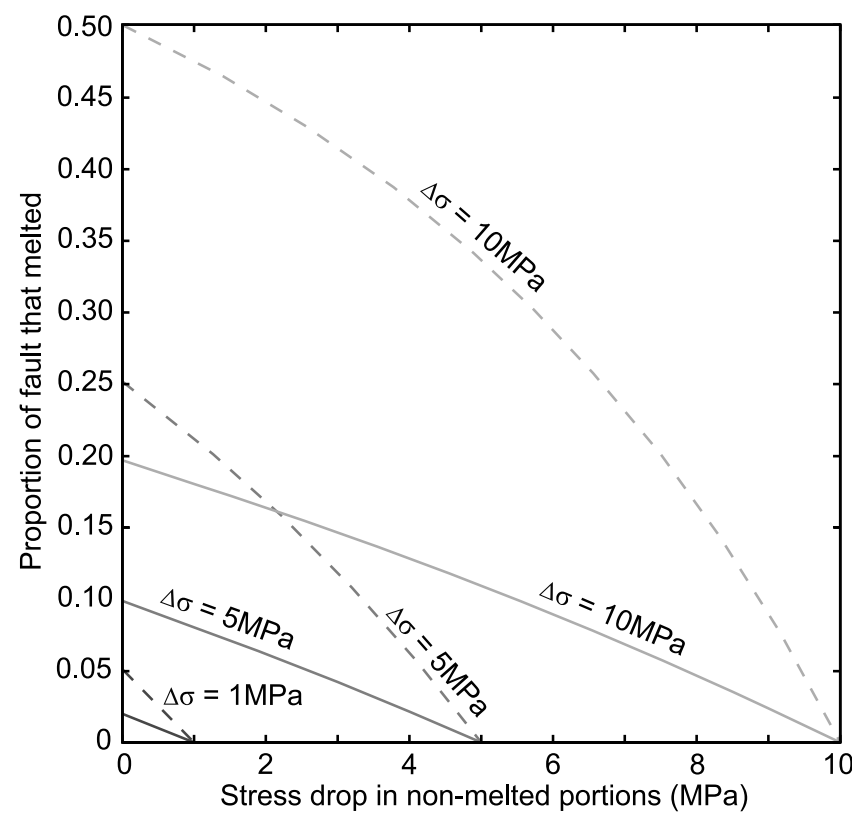

Figure 6. Plot showing the proportion of the fault that would have melted for macroscopic stress drops $(\Delta \sigma)$ of 1 , 5 and $10 \mathrm{MPa}$. Dashed curves are failure stress of $21 \mathrm{MPa}$ (rupture depth $=2.4 \mathrm{~km}$ ), solid curves $51 \mathrm{MPa}$ (rupture depth $=6 \mathrm{~km})$. The macroscopic mean stress drop $(\Delta \sigma)$ is averaged over the fault area as described in equation (2). Shear resistance of the melts in this plot are assumed to be $0.2 \mathrm{MPa}$, the highest value obtained in our analysis, lower values will result in smaller proportions of melting.

field evidence for hydrofracture in the Kings Canyon faults (indicative of high pore pressures), and the observation that melt formed suggests fluid pressures were low during slip.

[35] This estimate of $\Delta \sigma_{\mathrm{m}}$ is for the coseismic, dynamic stress drop accompanying melting, although if the quench time of the melt is much longer than the duration of rupture, then $\Delta \sigma_{\mathrm{m}}$ is also the local static stress drop. Seismological estimates of the dynamic stress drop are challenging as they rely on either extreme near-field data or model-dependent interpretations of far-field data. Nonetheless, most studies have found that dynamic stress drops averaged over a complete rupture are commonly $\sim 1 \mathrm{MPa}$ and do not exceed $10 \mathrm{MPa}$ [Brune, 1970; Heaton, 1990; Beeler et al., 2003; Malagnini et al., 2010]. The seismological studies also indicate that averaged over the rupture, the dynamic stress drops are comparable to the static stress drops [Kanamori and Anderson, 1975], even though theoretical and laboratory studies do suggest plausible re-strengthening processes [Del Gaudio et al., 2009; Nielsen et al., 2010b].

[36] Reconciling the seismological and the geological observations requires incorporating the heterogeneity of stress conditions on the rupture to connect the ruptureaveraged stress drop value to local values. The heterogeneous distribution of fault rocks, in particular pseudotachylytes, along the study area faults indicates complexity in the stress changes at the exposure scale.

[37] The pseudotachylyte patches in the SKF and other faults in the study area are $\sim 5$ to $10 \mathrm{~m}$ long and formed within larger ruptures [Kirkpatrick and Shipton, 2009]. If the paleo-seismic events that formed the pseudotachylytes in the study area conformed to historically recorded typical macroscopic dynamic stress drops, $\Delta \sigma$, the extremely high $\Delta \sigma_{\mathrm{m}}$ values must be balanced by low stress drops in the nonmelted portions of the fault, $\Delta \sigma_{\mathrm{r}}$. The results therefore imply that rupture-averaged dynamic stress drops were dominated by processes operating over small areas of the fault plane. They also suggest that small-scale heterogeneity in dynamic stress drop is characterized by the lengths of the pseudotachylyte patches (i.e., of the order of a few meters to $\sim 10 \mathrm{~m}$ ). A similar interpretation was suggested from measurements of coseismic slip on faults that form in single-jerk events where spatial fluctuations in slip indicate variations in stress drop [e.g., McGarr et al., 1979], but limited offset markers restrict the potential for quantifying the length scale over which variations occurred.

[38] The magnitude of stress drop variation is a function of the spatial distribution of pseudotachylytes in the fault. The balance between the stress drop in the melt, the stress drop in the non-melted parts and the macroscopic stress drop is a simple spatial average given by

$$
\Delta \sigma=\Delta \sigma_{r}(1-x)+\Delta \sigma_{m} x
$$

where $x$ is the proportion of the fault that melted. Using our lowest estimates of $\Delta \sigma_{\mathrm{m}}$ (highest $\sigma_{\mathrm{m}}$ ) and macroscopic dynamic stress drops $(\Delta \sigma)$ of 1,5 and $10 \mathrm{MPa}$ from seismological observations, we estimate the proportion of the fault that would have melted during the SKF paleo-earthquake for a range of possible $\Delta \sigma_{\mathrm{r}}$ values (Figure 6). The maximum amount of melting during the paleo-earthquake on the SKF would be $\sim 50 \%$ which occurs for the rupture depth of $2.4 \mathrm{~km}, \Delta \sigma=10 \mathrm{MPa}$ and $\Delta \sigma_{\mathrm{r}}=0$. The maximum depth constrained by the thermochronology is $6 \mathrm{~km}$ (i.e., $\Delta \sigma_{\mathrm{m}} \sim 51 \mathrm{MPa}$ ), for which equation (2) predicts that a maximum of $\sim 19 \%$ of the fault would have melted. This is more consistent with the qualitative field observations, and suggests greater depths implied by lower geothermal gradients are more likely than shallow rupture depths. Note that higher $\sigma_{\mathrm{m}}$ values would require smaller $\Delta \sigma_{\mathrm{m}}$ and consequently the predicted proportion of the fault that melted would increase, which is inconsistent with the field observations. Since the shear resistance during slip is effectively negligible, the result is not excessively rheology dependent as the melt resistance is much lower than the stress at failure.

[39] The high $\Delta \sigma_{\mathrm{m}}$ values imply that the dynamic stress drop varied spatially by at least an order of magnitude during a single rupture. As some melting evidently occurred during the earthquake, $\Delta \sigma_{\mathrm{r}}$, must have been less than $10 \mathrm{MPa}$, and could have been significantly lower. Such large stress variations during earthquake rupture have previously been inferred to explain near-source strong ground motions [e.g., Kostrov, 1974], but without direct observation of the processes causing the variation. Spatially variable dynamic stress drop also requires that dynamic weakening in the nonmelted parts of the fault was small, or that significant healing characterizes the final increments of slip in the non-melted parts of the rupture area. However, the fault rocks contain little information regarding the distances over which the dynamic stress drop changed from large to small. The pseudotachylytes pinch out along-strike into cataclasites, 
thinning gradually over a few $\mathrm{cm}$. If the dynamic stress drop switched abruptly from complete to very little over a few $\mathrm{cm}$, the step-changes in the stress drop of the order of tens of $\mathrm{MPa}$ would require failure of the surrounding rock, which is not observed in the field. It is more likely that the spatial variation in stress drop occurred more gradually over meters or more, perhaps modulated by the stiffness of the surrounding rock. This requires that in some places the stress drop in the cataclasistes was large (i.e., immediately adjacent to pseudotachylyte patches), but on average the stress drop in the cataclasites must have been small.

[40] In many respects, the study area faults are classic examples of pseudotachylyte generating faults [Sibson and Toy, 2006]. They cut low porosity, quartz-rich, crystalline rocks and were active at shallow to mid crustal depths. Pseudotachylytes are less often identified in exhumed plate boundary faults, which typically contain gouge and cataclasite without evidence for melting. It is interesting to note that the maximum proportion of the Sierra faults that could have melted is $\leq 50 \%$ (Figure 6), and was likely $<20 \%$; another reason for the apparent scarcity of frictional melt products in exhumed faults (in addition to previously discussed factors [Griffith et al., 2008; Kirkpatrick et al., 2009]) is that only a small area of any earthquake rupture would melt reducing the likelihood of finding pseudotachylytes in an exposure of an exhumed fault.

[41] The distribution of deformation products in the exhumed SKF fault reflects the spatial variation in coseismic source parameters. The key control on the onset of melting was the architecture of the fault. Melting occurred where meso-scale 'asperities', or bumps, on either side of the fault were locally in contact. At this place on the fault, the thickness of the slip zone [Kirkpatrick and Shipton, 2009] was narrow, and normal stresses were likely higher [Chester and Chester, 2000; Griffith et al., 2010]. Where the slip zone is narrow, frictional heating raised the temperature quicker and resulted in melting after smaller amounts of slip than where it is wider. Higher stresses at the asperity may have caused more rapid frictional heating. This resulted in diverging stress trajectories for the melted and non-melted parts of the fault. As faults from a variety of lithologies and tectonic settings have similar roughness at the scales of seismic slip [e.g., Sagy et al., 2007; Brodsky et al., 2011], we expect that slip zone thickness would vary with similar properties on a wide range of faults. Therefore, we predict that the onset of any thermally activated weakening mechanism [Di Toro et al., 2011] will be spatially variable in the same way as suggested by the pseudotachylyte patches and that the pattern of small proportions of a rupture area experiencing high stress drops is common.

[42] Constraints on earthquake source parameters can be obtained by parameterizing the fault plane and inverting seismic data for slip and moment release histories [e.g., Bouchon, 1997; Ma et al., 2001]. Numerous studies show that the seismic source is complex [e.g., Hanks, 1979], but there are few constraints on the degree of complexity at short length scales because attenuation of seismic energy and scattering from structural heterogeneity in the shallow crust limits the spatial resolution of these inversions to kilometers. Variations that occur over shorter length scales are not deterministically imaged by seismological source inversions. The results of this study show that fault architecture and the distribution of fault rocks can be used to constrain the physics of earthquake rupture at length scales below the resolution of seismic inversions.

\section{Conclusions}

[43] Integrating ${ }^{40} \mathrm{Ar} /{ }^{39} \mathrm{Ar}$ dating of pseudotachylytes and the time-temperature path of the host rock shows that the depth of pseudotachylyte formation in the study area faults was 2.4 to $6 \mathrm{~km}$. At these depths, the stress at failure was up to $\sim 51 \mathrm{MPa}$ for optimally oriented faults. As the shear resistance of the melt layers was $<1 \mathrm{MPa}$, the dynamic stress drop associated with pseudotachylyte formation was complete suggesting stress drops of similar magnitude to those measured experimentally do occur during earthquakes. By considering the macroscopic estimates of dynamic static stress drop measured seismologically, we have demonstrated that at mid crustal conditions the dynamic stress drop over melt bearing and non-melt bearing parts of the fault differs by at least an order of magnitude. We conclude that the extent of pseudotachylytes exposed in exhumed faults represent the minimum length scale over which seismic source parameters vary, i.e., 1 to $10 \mathrm{~m}$. Although it has long been known that stress must be highly heterogeneous during earthquakes, the pseudotachylyte observations combined with the depth constraints provide a quantitative estimate of the degree and scale of heterogeneity.

[44] Acknowledgments. Ross Dymock (SUERC) is thanked for assistance with sample preparation and Jim Imlach (SUERC) is thanked for technical assistance. Ewan Brooker and Mark Wildman (University of Glasgow) and Luigia DiNicola (SUERC) are thanked for assistance with (U-Th)/He analyses. We thank Thorne Lay and Christie Rowe for providing extremely helpful comments on earlier versions of the manuscript. Thoughtful and constructive reviews by Giulio Di Toro and Ashley Griffith helped improve the manuscript greatly. This project was funded by NERC Isotope Geosciences Facilities grant IP/1110/0509, University of Glasgow John Roberston Bequest grant JR09/08 and NERC grant NE/E005365/1, NSF EAR award 0948740. K.J.D. was funded by SAGES. Thanks to Sequoia and Kings Canyon National Park for access and sampling permits.

\section{References}

Andersen, T. B., K. Mair, H. Austrheim, Y. Y. Podladchikov, and J. C. Vrijmoed (2008), Stress release in exhumed intermediate and deep earthquakes determined from ultramafic pseudotachylyte, Geology, 36, 995-998, doi:10.1130/G25230A.1.

Austrheim, H., and T. M. Boundy (1994), Pseudotachylytes generated during seismic faulting and eclogitization of the deep crust, Science, 265, 82-83, doi:10.1126/science.265.5168.82.

Barker, S. L. L. (2005), Pseudotachylyte-generating faults in central Otago, New Zealand, Tectonophysics, 397(3-4), 211-223, doi:10.1016/j.tecto. 2004.12.005.

Beeler, N., T. F. Wong, and S. Hickman (2003), On the expected relationships among apparent stress, static stress drop, effective shear fracture energy, and efficiency, Bull. Seismol. Soc. Am., 93(3), 1381-1389, doi:10.1785/0120020162.

Bird, D. K., and A. R. Spieler (2004), Epidote in geothermal systems, Rev. Mineral. Geochem., 56, 235-300, doi:10.2138/gsrmg.56.1.235.

Bjørk, T. E., K. Mair, and H. Austrheim (2009), Quantifying granular material and deformation: Advantages of combining grain size, shape, and mineral phase recognition analysis, J. Struct. Geol., 31, 637-653, doi:10.1016/j.jsg.2009.03.020.

Bouchon, M. (1997), The state of stress on some faults of the San Andreas system as inferred from near-field strong motion data, J. Geophys. Res., 102, 11,731-11,744, doi:10.1029/97JB00623.

Brodsky, E. E., C. D. Rowe, F. Meneghini, and J. C. Moore (2009), A geological fingerprint of low-viscosity fault fluids mobilized during an earthquake, J. Geophys. Res., 114, B01303, doi:10.1029/2008JB005633.

Brodsky, E. E., J. J. Gilchrist, A. Sagy, and C. Collettini (2011), Faults smooth gradually as a function of slip, Earth Planet. Sci. Lett., 302, 185-193, doi:10.1016/j.eps1.2010.12.010. 
Bruhn, R. L., W. T. Parry, W. A. Yonkee, and T. Thompson (1994), Fracturing and hydrothermal alteration in normal fault zones, Pure Appl. Geophys., 142(3-4), 609-644, doi:10.1007/BF00876057.

Brune, J. N. (1970), Tectonic stress and the spectra of seismic shear waves from earthquakes, J. Geophys. Res., 75, 4997-5009, doi:10.1029/ JB075i026p04997.

Chester, J. S., and F. M. Chester (2000), Stress and deformation along wavy frictional faults, J. Geophys. Res., 105, 23,421-23,430, doi:10.1029/ 2000JB900241.

Clark, M. K., G. Maheo, J. Saleeby, and K. A. Farley (2005), The nonequilibrium landscape of the southern Sierra Nevada, California, GSA Today, 15, 4-10, doi:10:1130/1052-5173(2005)015.

Cowan, D. S. (1999), Do faults preserve a record of seismic slip? A field geologist's opinion, J. Struct. Geol., 21, 995-1001, doi:10.1016/S01918141(99)00046-2.

Del Gaudio, P., G. Di Toro, R. Han, T. Hirose, S. Nielsen, T. Shimamoto, and A. Cavallo (2009), Frictional melting of peridotite and seismic slip J. Geophys. Res., 114, B06306, doi:10.1029/2008JB005990.

Dilles, J. H., and M. T. Einaudi (1992), Wall rock alteration and hydrothermal flow paths about the Ann-Mason porphyry copper deposit, Nevada: A 6 km vertical reconstruction, Econ. Geol., 87, 1963-2001, doi:10.2113/gsecongeo.87.8.1963

Di Toro, G., and G. Pennacchioni (2004), Superheated friction-induced melts in zoned pseudotachylytes within the Adamello tonalites (Italian southern Alps), J. Struct. Geol., 26, 1783-1801, doi:10.1016/j. jsg.2004.03.001.

Di Toro, G., G. Pennacchioni, and G. Teza (2005), Can pseudotachylytes be used to infer earthquake source parameters? An example of limitations in the study of exhumed faults, Tectonophysics, 402(1-4), 3-20, doi:10.1016/j.tecto.2004.10.014.

Di Toro, G., T. Hirose, S. Nielsen, G. Pennacchioni, and T. Shimamoto (2006), Natural and experimental evidence of melt lubrication of faults during earthquakes, Science, 311(5761), 647-649, doi:10.1126/ science. 1121012 .

Di Toro, G., et al. (2011), Fault lubrication during earthquakes, Nature, 471, 494-498, doi:10.1038/nature09838.

Di Vincenzo, G., S. Rocchi, F. Rossetti, and F. Storti (2004), ${ }^{40} \mathrm{Ar}-{ }^{39} \mathrm{Ar}$ dating of pseudotachylytes: The effect of clast-hosted extraneous argon in Cenozoic fault-generated friction melts from the West Antarctic Rift System, Earth Planet. Sci. Lett., 223, 349-364, doi:10.1016/ j.eps1.2004.04.042.

Dobson, K. J., F. M. Stuart, T. J. Dempster, and EIMF (2008), U and Th zonation in Fish Canyon Tuff zircons: Implications for a zircon (U-Th) He standard, Geochim. Cosmochim. Acta, 72, 4745-4755, doi:10.1016/ j.gca.2008.07.015

Dobson, K. J., C. Persano, and F. M. Stuart (2009), Quantitative constraints on mid- to shallow crustal processes using the zircon (U-Th)/He thermochronometer, in Thermochronological Methods: From Palaeotemperature Constraints to Landscape Evolution Models, edited by F. Lisker, B. Ventura, and U. A. Glasmacher, Geol. Soc. Spec. Publ., 324, 47-56, doi:10.1144/SP324.4

Dobson, K. J., F. M. Stuart, and T. J. Dempster (2010), Thermal history of the Hebridean Igneous Province (HIP): How long has the HIP been cool? J. Geol. Soc., 167(5), 973-984, doi:10.1144/0016-76492009-154.

Dumitru, T. A. (1990), Subnormal Cenozoic geothermal gradients in the extinct Sierra Nevada magmatic arc: Consequences of Laramide and post-Laramide shallow-angle subduction, J. Geophys. Res., 95, 4925-4941, doi:10.1029/JB095iB04p04925.

Farley, K. A., R. A. Wolf, and L. T. Silver (1996), The effects of long alpha-stopping distances on (U-Th)/He ages, Geochim. Cosmochim. Acta , 60, 4223-4229, doi:10.1016/S0016-7037(96)00193-7.

Fialko, Y., and Y. Khazan (2005), Fusion by earthquake fault friction: Stick or slip?, J. Geophys. Res., 110, B12407, doi:10.1029/2005JB003869.

Foeken, J. P. T., F. M. Stuart, K. J. Dobson, C. Persano, and D. Vilbert (2006), A diode laser system for heating minerals for (U-Th)/He chronometry, Geochem. Geophys. Geosyst., 7, Q04015, doi:10.1029/2005GC001190.

Ghiorso, M. S., and R. O. Sack (1995), Chemical mass transfer in magmatic processes IV: A revised and internally consistent thermodynamic model for the interpolation and extrapolation of liquid-solid equilibria in magmatic systems at elevated temperatures and pressures, Contrib. Mineral. Petrol., 119, 197-212, doi:10.1007/BF00307281.

Griffith, W. A., G. Di Toro, G. Pennacchioni, and D. D. Pollard (2008), Thin pseudotachylytes in faults of the Mt. Abbot Quadrangle, Sierra Nevada California: Physical constraints on seismic slip, J. Struct. Geol., 30, 1086-1094, doi:10.1016/j.jsg.2008.05.003.

Griffith, W. A., S. Nielsen, G. Di Toro, and F. A. S. Smith (2010), Rough faults, distributed weakening, and off- fault deformation, J. Geophys. Res., 115, B08409, doi:10.1029/2009JB006925.
Guilbert, J. M., and C. F. Park (1986), The Geology of Ore Deposits, Freeman, New York.

Hanks, T. (1979), b values and $\omega-\gamma$ seismic source models: Implications for tectonic stress variations along active crustal fault zones and the estimation of high-frequency strong ground motion, J. Geophys. Res., 84 (B5), 2235-2242, doi:10.1029/JB084iB05p02235.

Heaton, T. H. (1990), Evidence for and implications of self-healing pulses of slip in earthquake rupture, Phys. Earth Planet. Inter., 64(1), 1-20, doi:10.1016/0031-9201(90)90002-F.

Hess, K.-U., and D. B. Dingwell (1996), Viscosities of hydrous leucogranite melts: A non-Arrhenian model, Am. Mineral., 81, 1297-1300.

Hourigan, J. K., P. W. Reiners, and M. T. Brandon (2005), U-Th zonationdependent alpha-ejection in (U-Th)/He chronometry, Geochim. Cosmochim. Acta, 69, 3349-3365, doi:10.1016/j.gca.2005.01.024.

House, M. A., B. P. Wernicke, and K. A. Farley (2001), Paleogeomorphology of the Sierra Nevada, California, from (U/Th)/He ages in apatite, Am. J. Sci., 301, 77-102, doi:10.2475/ajs.301.2.77.

Hurford, A. J., and P. F. Green (1983), The zeta age calibration of fission track dating, Isot. Geosci., 1, 285-317.

Jeffreys, H. (1942), On the mechanics of faulting, Geol. Mag., 79, 291-295, doi:10.1017/S0016756800076019.

Kanamori, H., and D. Anderson (1975), Theoretical basis of some empirical relations in seismology, Bull. Seismol. Soc. Am., 65, 1023-1095.

Kano, Y., R. Fujio, H. Ito, T. Yanagidani, S. Nakao, and K. F. Ma (2006), Heat signature on the Chelungpu Fault associated with the 1999 Chi-Chi, Taiwan earthquake, Geophys. Res. Lett., 33, L14306, doi:10.1029/ 2006GL026733

Ketcham, R. A. (2005), Forward and inverse modeling of low-temperature thermochronometry data, Rev. Mineral. Geochem., 58, 275-314, doi:10.2138/rmg.2005.58.11.

Kirkpatrick, J. D., and Z. K. Shipton (2009), Geologic evidence for multiple slip weakening mechanisms during seismic slip in crystalline rock, J. Geophys. Res., 114, B12401, doi:10.1029/2008JB006037.

Kirkpatrick, J. D., Z. K. Shipton, J. P. Evans, S. Micklethwaite, S. J. Lim, and P. McKillop (2008), Strike-slip fault terminations at seismogenic depths: The structure and kinematics of the Glacier Lakes fault, Sierra Nevada United States, J. Geophys. Res., 113, B04304, doi:10.1029/ 2007JB005311.

Kirkpatrick, J. D., Z. K. Shipton, and C. Persano (2009), Pseudotachylytes: Rarely generated, rarely preserved, or rarely reported?, Bull. Seismol. Soc. Am., 99, 382-388, doi:10.1785/0120080114.

Kostrov, V. (1974), Seismic moment and energy of earthquakes and seismic flow of rock, Phys. Solid Earth, 1, 13-21.

Kuiper, K. F., A. Deino, F. J. Hilgen, W. Krijgsman, P. R. Renne, and J. R. Wijbrans (2008), Synchronizing the rock clocks of Earth history, Science, 320, 500-504, doi:10.1126/science.1154339.

Ma, K.-F., J. Mori, S.-J. Li, and S. B. Yu (2001), Spatial and temporal distribution of slip for the 1999 Chi-Chi, Taiwan, earthquake, Bull. Seismol. Soc. Am., 91, 1069-1087, doi:10.1785/0120000728.

Magloughlin, J. F., and J. G. Spray (1992), Frictional melting processes and products in geological-materials: Introduction and discussion, Tectonophysics, 204(3-4), 197-204, doi:10.1016/0040-1951(92)90307-R.

Malagnini, L., S. Nielsen, K. Mayeda, and E. Boschi (2010), Energy radiation from intermediate- to large-magnitude earthquakes: Implications for dynamic fault weakening, J. Geophys. Res., 115, B06319, doi:10.1029/ 2009JB006786

Mark, D. F., D. N. Barfod, F. M. Stuart, and J. Imlach (2009), The ARGUS multicollector noble gas mass spectrometer: Performance for 40Ar/39Ar geochronology, Geochem. Geophys. Geosyst., 10, Q0AA02, doi:10.1029/2009GC002643.

Marsh, B. D. (1981), On the crystallinity, probability of occurrence, and rheology of lava and magma, Contrib. Mineral. Petrol., 78, 85-98, doi:10.1007/BF00371146.

Mastin, L. G. (2002), Insights into volcanic conduit flow from an opensource numerical model, Geochem. Geophys. Geosyst., 3(7), 1037, doi:10.1029/2001GC000192.

Mastin, L. G., and M. S. Ghiorso (2000), A numerical program for steady state flow of magma gas mixtures through vertical eruptive conduits, U.S. Geol. Surv. Open File Rep., 00-209.

McGarr, A., S. M. Spottiswoode, C. Gay, and W. D. Ortlepp (1979), Observations relevant to seismic driving stress, stress drop, and efficiency, J. Geophys. Res., 84(B5), 2251-2261, doi:10.1029/JB084iB05p02251.

Moore, J. G. (1978), Geologic map of the Marion Peak Quadrangle, Fresno County, 1:130,000, U.S. Geol. Surv., Menlo Park, Calif.

Mueller, S., E. W. Llewellin, and H. M. Mader (2010), The rheology of suspensions of solid particles, Proc. R. Soc. A, 466, 1201-1228, doi:10.1098/rspa.2009.0445. 
Mueller, S., E. W. Llewellin, and H. M. Mader (2011), The effect of particle shape on suspension viscosity and implications for magmatic flows, Geophys. Res. Lett., 38, L13316, doi:10.1029/2011GL047167.

Nielsen, S., G. Di Toro, T. Hirose, and T. Shimamoto (2008), Frictiona melt and seismic slip, J. Geophys. Res., 113, B01308, doi:10.1029 2007JB005122.

Nielsen, S., P. Mosca, G. Giberti, G. Di Toro, T. Hirose, and T. Shimamoto (2010a), On the transient behavior of frictional melt during seismic slip, J. Geophys. Res., 115, B10301, doi:10.1029/2009JB007020.

Nielsen, S., G. Di Toro, and A. Griffith (2010b), Friction and roughness of a melting rock surface, Geophys. J. Int., 182, 299-310, doi:10.1111/ j.1365-246X.2010.04607.x.

Niemeijer, A. R., G. Di Toro, S. Nielsen, and F. Di Felice (2011), Frictional melting of gabbro under extreme experimental conditions of norma stress, acceleration and sliding velocity, J. Geophys. Res., 116, B07404, doi:10.1029/2010JB008181.

Nier, A. O. (1950), A redetermination of the relative abundances of the isotopes of carbon, nitrogen, oxygen, argon, and potassium, Phys. Rev., 77, 789-793, doi:10.1103/PhysRev.77.789.

Pachell, M. A., and J. P. Evans (2002), Growth, linkage, and termination processes of a 10-km-long strike-slip fault in jointed granite: The Gemin fault zone, Sierra Nevada, California, J. Struct. Geol., 24, 1903-1924, doi:10.1016/S0191-8141(02)00027-5.

Pennacchioni, G., G. Di Toro, P. Brack, L. Menegon, and I. M. Villa (2006), Brittle-ductile-brittle deformation during cooling of tonalite (Adamello, Southern Italian Alps), Tectonophysics, 427, 171-197, doi:10.1016/j.tecto.2006.05.019.

Persano, C., D. N. Barfod, F. M. Stuart, and P. Bishop (2007), Constraints on early Cenozoic underplating-driven uplift and denudation of western Scotland from low temperature thermochronometry, Earth Planet. Sci. Lett., 263, 404-419, doi:10.1016/j.eps1.2007.09.016.

Philpotts, A. R. (1964), Origin of pseudotachylytes, Am. J. Sci., 262, 1008-1035, doi:10.2475/ajs.262.8.1008.

Ray, S. K. (1999), Transformation of cataclastically deformed rocks to pseudotachylyte by pervasion of frictional melt: Inferences from clast size analysis, Tectonophysics, 301, 283-304, doi:10.1016/S0040-1951(98) 00229-7.

Reiners, P. W., T. L. Spell, S. Nicolescu, and K. A. Zanetti (2004), Zircon (U-Th)/He thermochronometry: He diffusion and comparisons with ${ }^{40} \mathrm{Ar} /{ }^{39} \mathrm{Ar}$ dating, Geochim. Cosmochim. Acta, 68, 1857-1887, doi:10.1016/j.gca.2003.10.021.

Renne, P. R., C. C. Swisher, A. L. Deino, D. B. Karner, T. L. Owens, and D. J. DePaolo (1998), Intercalibration of standards, absolute ages and uncertainties in Ar/Ar dating, Chem. Geol., 145, 117-152, doi:10.1016/ S0009-2541(97)00159-9.

Rothstein, D. A., and C. E. Manning (2003), Geothermal gradients in continental magmatic arcs: Constraints from the eastern Peninsular Ranges batholith, Baja California, México, in Tectonic Evolution of Northwestern México and the Southwestern USA, edited by S. E. Johnson et al., Spec. Pap. Geol. Soc., 374, 337-354.
Sagy, A., E. E. Brodsky, and G. J. Axen (2007), Evolution of fault-surface roughness with slip, Geology, 35, 283-286, doi:10.1130/G23235A.1.

Shaw, H. R. (1972), Viscosities of magmatic silicate liquids: An empirical method of prediction, Am. J. Sci., 272, 870-893, doi:10.2475/ ajs.272.9.870

Sherlock, S. C., K. A. Jones, and R. G. Park (2008), Grenville-age pseudotachylite in the Lewisian: Laserprobe ${ }^{40} \mathrm{Ar} /{ }^{39} \mathrm{Ar}$ ages from the Gairloch region of Scotland (UK), J. Geol. Soc., 165, 73-83, doi:10.1144/001676492006-134.

Sibson, R. H. (1974), Frictional constraints on thrust, wrench and normal faults, Nature, 249, 542-544, doi:10.1038/249542a0.

Sibson, R. H. (1975), Generation of pseudotachylyte by ancient seismic faulting, Geophys. J. R. Astron. Soc., 43, 775-794, doi:10.1111/j.1365246X.1975.tb06195.x.

Sibson, R. H. (1982), Fault zone models, heat-flow, and the depth distribution of earthquakes in the continental-crust of the United States, Bull. Seismol. Soc. Am., 72(1), 151-163.

Sibson, R. H. (1985), A note on fault reactivation, J. Struct. Geol., 7, 751-754, doi:10.1016/0191-8141(85)90150-6.

Sibson, R. H. (2003), Thickness of the seismic slip zone, Bull. Seismol. Soc. Am., 93(3), 1169-1178, doi:10.1785/0120020061.

Sibson, R. H., and V. G. Toy (2006), The habitat of fault-generated pseudotachylyte: Presence vs. absence of friction-melt, in Earthquakes. Radiated Energy and the Physics of Faulting, Geophys. Monogr. Ser., vol. 170, edited by R. E. Abercrombie et al., pp. 153-166, AGU, Washington, D. C., doi:10.1029/170GM16.

Spray, J. G. (1992), A physical basis for the frictional melting of some rockforming minerals, Tectonophysics, 204, 205-221, doi:10.1016/00401951(92)90308-S

Spray, J. G. (1993), Viscosity determinations of some frictionally generated Silicate melts: Implications for fault zone rheology at high strain rates, J. Geophys. Res., 98, 8053-8068, doi:10.1029/93JB00020.

Spray, J. G. (2010), Frictional melting processes in planetary materials: From hypervelocity impact to earthquakes, Annu. Rev. Earth Planet. Sci., 38, 221-254, doi:10.1146/annurev.earth.031208.100045.

Steiger, R. H., and E. Jäger (1977), Subcomission on geochronology: Convention on use of decay constants in geochronology and cosmochronology, Earth Planet. Sci. Lett., 36, 359-362, doi:10.1016/0012-821X(77) 90060-7.

Ujiie, K., H. Yamaguchi, A. Sakaguchi, and T. Shoichi (2007), Pseudotachylytes in an ancient accretionary complex and implications for melt lubrication during subduction zone earthquakes, J. Struct. Geol., 29 , 599-613, doi:10.1016/j.jsg.2006.10.012.

Warr, L. N., B. A. van der Pluijm, and S. Tourscher (2007), The age and depth of exhumed friction melts along the Alpine fault, New Zealand, Geology, 35(7), 603-606, doi:10.1130/G23541A.1.

Wells, D. L., and K. J. Coppersmith (1994), New empirical relationships among magnitude, rupture length, rupture width, rupture area, and surface displacement, Bull. Seismol. Soc. Am., 84, 974-1002.

Yardley, B. W. D. (1989), An Introduction to Metamorphic Petrology, Longman, New York. 